\section{Hydroxyapatite in the Pathogenesis of Cystic Fibrosis}

\author{
KATHRYN L. WARTON, JEANETTE BLOMFIELD
}

British Medical fournal, 1971, 3, 570-571

\section{Summary}

Submandibular saliva collected from cystic fibrosis patients and control subjects was separated by centrifugation into an insoluble deposit and a clear supernatant. The resulting calcium and phosphorus analyses performed on both fractions warranted a closer investigation as a consistent $\mathrm{Ca} / \mathrm{P}$ molar ratio of 1.5 was found in the deposit of the cystic fibrosis patients, while no consistent ratio $>1.0$ was found in the deposit of the control subjects. The expected result, that calcium and phosphorus in the deposit of cystic fibrosis patients is present as the solid phase of hydroxyapatite, was confirmed by a detailed comparison of $x$-ray powder diffraction patterns of an ashed sample of this deposit and a similarly treated synthetic sample of hydroxyapatite.

\section{Introduction}

The submandibular saliva of patients suffering from cystic fibrosis has been reported to be turbid compared with the clear submandibular saliva of control subjects and also to possess high calcium and protein levels (Chernick et al., 1961; Gugler et al., 1967; Mandel et al., 1969). These factors have been associated with the presence of an insoluble calcium-glycoprotein complex (di Sant'Agnese and Talamo, 1967) and have been proposed as the cause of widespread mucous obstruction in cystic fibrosis (Chernick et al., 1961; di Sant'Agnese and Talamo, 1967).

The submandibular gland produces a seromucoid secretion not dissimilar to the secretion of the tracheobronchial tract, and the saliva of this gland thus permits analyses to be made from a pathologically affected gland relatively free of contaminants (Chernick et al., 1961). In an attempt to gain further insight into the abnormality of the secretions resulting in bronchial obstruction it was decided to examine, in vitro, the inorganic nature of the insoluble submandibular deposit. In this paper it is shown that calcium and phosphorus are present as hydroxyapatite in cystic fibrosis submandibular saliva.

\section{Subjects and Methods}

Thirty-five ambulatory cystic fibrosis patients were studied; the group consisted of 19 males aged 4 to 18 years and 16 females aged 5 to 21 years. As controls, 28 healthy subjects of similar age and sex distribution were selected.
The method of saliva collection was based on the procedures of Mandel et al. (1969), the glands being stimulated by citric acid before collection of the submandibular saliva. After a preliminary introductory collection, four collections were performed where possible on all subjects. All samples were centrifuged at $37,000 \mathrm{~g}$ with a minimum time lag after collection, yielding an insoluble deposit and a clear supernatant. This deposit was dissolved in $4 \mathrm{~N}$ hydrochloric acid (to original sample volume) and analyses were performed on both supernatant and dissolved deposit. Calcium was analysed by atomic absorption spectrophotometry, lanthanum chloride being used as diluent (Gow, 1965). Phosphorus was determined by the colorimetric ascorbic acid molybdate method (Chen et al., 1956) and the results were expressed as $\mathrm{HPO}_{4}{ }^{2-} \mathrm{mEq} / 1$. The $x$-ray powder diffraction patterns were obtained by 14-hour exposures of the samples, $\mathrm{Cu} \mathrm{K} \propto$ (Ni filtered) $x$-radiation being used. The samples (saliva deposit and synthetic sample of hydroxyapatite) had been previously ashed at $450^{\circ}$ overnight and packed in $0.5 \mathrm{~mm}$ (internal diameter) Lindeman glass capillaries.

\section{Results}

The total calcium concentration was $>3.5 \mathrm{mEq} / 1$. in $85 \%$ of the cystic fibrosis samples (mean $4.61 \mathrm{mEq} / 1$.), but $>3.5 \mathrm{mEq} / 1$. in only $17 \%$ of the control samples (mean $2.91 \mathrm{mEq} / 1$.). In addition, $71 \%$ of the cystic fibrosis samples had a deposit calcium $>1.0 \mathrm{mEq} / 1$. (mean $1.58 \mathrm{mEq} / 1$.) in contrast to $22 \%$ of the control samples (mean $0.63 \mathrm{mEq} / 1$.). These results clearly show the high levels of total and insoluble calcium in the submandibular saliva of cystic fibrosis patients.

Little difference was found in mean total phosphorus between the two groups of subjects, the values being 6.93 and 7.06 $\mathrm{mEq} / 1$. for cystic fibrosis patients and control subjects respectively and the corresponding mean deposit values were 1.04 and $0.65 \mathrm{mEq} / 1$.

The relationship of $\mathrm{Ca}^{2+}$ and $\mathrm{HPO}_{4}{ }^{2-}$ in the insoluble deposit is shown in Fig. 1. A molar $\mathrm{Ca} / \mathrm{P}$ ratio of 1.5 is manifest in the cystic fibrosis patients while no consistent ratio $>1.0$ can
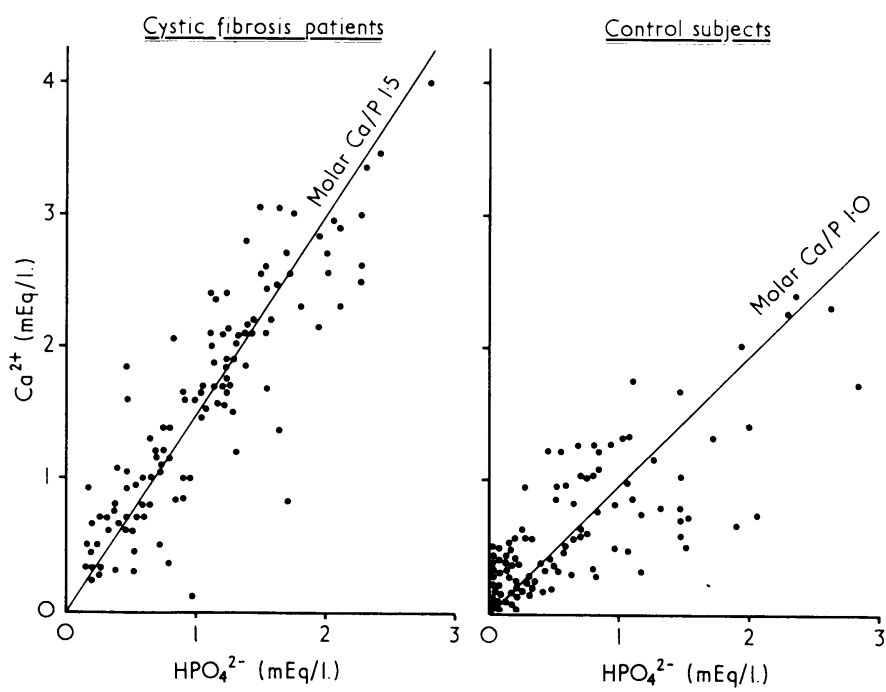

FIG. 1-Relationship between deposit calcium and phosphorus.

be found in the control subjects. The structure of such a calcium phosphate complex bearing a molar $\mathrm{Ca} / \mathrm{P}$ ratio of 1.5 is
Children's Medical Research Foundation, Royal Alexandra Hospital for Children, Sydney, N.S.W. 2050, Australia

KATHRYN L. WARTON, B.sC., Research Assistant

JEANETTE BLOMFIELD, M.SC., F.A.A.C.B., Senior Research Officer 
identified in Fig. 2 by detailed comparison of the $x$-ray powder diffraction pattern with a synthetic hydroxyapatite sample (molar $\mathrm{Ca} / \mathrm{P}$ 1.64).

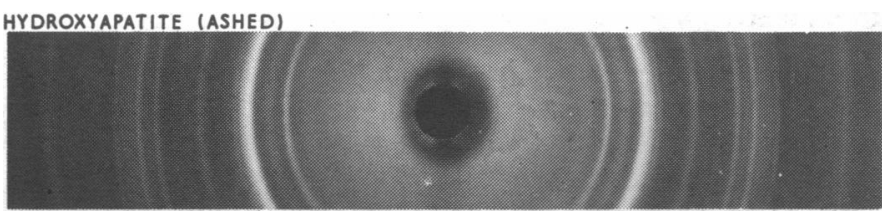

SALIVA PRECIPITATE (ASHED)

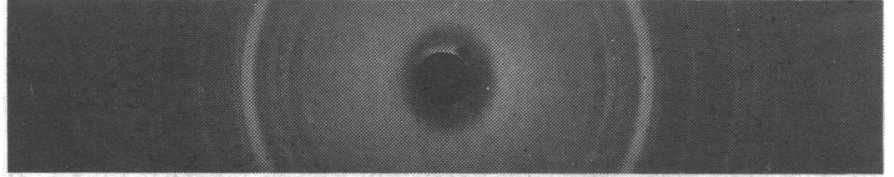

FIG. $2-X$-ray powder diffraction patterns after 15 hours at $450^{\circ}$.

\section{Discussion}

In a calcium phosphate system the solid phase which precipitates initially is secondary calcium phosphate, but at physiological pH the only solid phase which is stable is hydroxyapatite, which is formed by subsequent hydrolysis of secondary calcium phosphate (Neuman and Neuman, 1958). The high concentration of calcium in cystic fibrosis submandibular saliva induces such a precipitation as is evidenced by our finding of this stable form of calcium phosphate in the insoluble deposit.

Kwart and Shashoua (1957) proposed that calcium ions form the cross-links of a mucopolysaccharide to a mucoprotein in the formation of snail mucus. Dische (1964) reported that mammalian mucus consisting of glycoproteins can appear in the form of either a gel or a solute, the transition from each state being affected by many factors. He reported that the pathogenetic factors in mucus can be related to its tendency to form, with suspended solid particles, gels of high structural viscosity.

Braddock et al. (1970) reported that the ionic ratio of calcium to divalent phosphorus in the turbid saliva of cystic fibrosis patients was unity and in the non-turbid saliva of control subjects was 0.4 . These workers inferred the possible existence of a positively charged colloidal calcium phosphate in turbid saliva which causes an aggregation of negative sialic acid groups attached to the salivary proteins, thus producing the turbidity. Data obtained on calcium and phosphorus determinations with sputum samples from children with cystic fibrosis suggest that a similar mechanism may be responsible for the formation of the abnormal tracheobronchial secretions (Braddock et al., 1971).

Boat (1970) compared a highly purified calcium precipitable protein from submandibular saliva of cystic fibrosis and normal subjects and found no consistent differences. Specific factors were shown to enhance in vitro precipitation of this protein such as increasing calcium and protein concentrations and increasing $\mathrm{pH}$ above 7 . It was concluded that raised calcium concentration is the major factor responsible for turbidity in submandibular saliva of cystic fibrosis patients.

Gugler et al. (1967), using polyacrylamide gel electrophoresis, observed that by decreasing the raised calcium levels in turbid cystic fibrosis submandibular saliva the gross appearance and the electrophoretic pattern became similar to that of normal saliva. They also observed that by conversely increasing the calcium levels in normal submandibular saliva a turbid appearance resulted and the electrophoretic pattern became identical to that of cystic fibrosis saliva, inferring that submandibular saliva in both normal and cystic fibrosis patients contains glycoproteins whose size and configuration are influenced by ionic calcium.

Our results have shown that while the levels of phosphorus are essentially the same in the two groups of patients, the higher concentration of calcium in the submandibular saliva of cystic fibrosis patients is responsible for the presence of hydroxyapatite in the insoluble deposit. Gugler's demonstration that the addition of calcium to normal submandibular saliva yields an identical saliva in appearance and electrophoretic pattern to cystic fibrosis saliva is presumably due to the simultaneous precipitation of hydroxyapatite and protein, once the critical ion product needed for precipitation is exceeded in regard to calcium and phosphate (Neuman and Neuman, 1958).

Calcium is known to be increased in other cystic fibrosis mucous secretions, including tracheobronchial secretions (Chernick and Barbero, 1959), duodenal contents (Kopito and Shwachman, 1964), meconium (Kopito and Shwachman, 1966), and seminal fluid (Rule et al., 1970). It remains to be determined whether calcium precipitates as hydroxyapatite in these mucous secretions. Arterial metastatic calcification has been reported in two young cystic fibrosis patients (Kuhn et al., 1970).

Our results suggest that the mucous obstruction of respiratory tract, gastrointestinal tract, and reproductive tract of cystic fibrosis patients may be due to the presence of highly polymerized units of glycoprotein and hydroxyapatite.

We thank Professor H. C. Freeman and Mr. C. B. Acland, department of inorganic chemistry, University of Sydney, for their $x$-ray diffraction analyses and Dr. E. F. McFarlane and Mr. K. B. Peterson, department of physical chemistry, University of Sydney, for the gift of a synthetic sample of hydroxyapatite. We are grateful to Dr. J. M. Brown, Royal Alexandra Hospital for Children, Sydney, and the Cystic Fibrosis Association of New South Wales through whom we obtained cystic fibrosis volunteers for the saliva collection and to the latter for partial financial support of this work.

\section{References}

Boat, T. F. (1970). In Cystic Fibrosis Club Abstracts, Eleventh Annua Meeting, Atlantic City, p. 30.

Braddock, L. I., Nagelberg, I., Delmelle, E., and Barbero, G. J. (1970). In Cystic Fibrosis Club Abstracts, Eleventh Annual Meeting, Atlantic City, p. 31.

Braddock, L. I., Delmelle, E., Nagelberg, I., and Barbero, G. J. (1971). In Cystic Fibrosis Club Abstracts, Twelfth Annual Meeting, Atlantic

Chen, P. S., Toribara, T. Y., and Warner, H. (1956). Analytical Chemistry, $28,1756$.

Chernick, W. S., and Barbero, G. J. (1959). Pediatrics, 24, 739.

Chernick, W. S., Barbero, G. J., and Parkins, F. M. (1961). Fournal of Pediatrics, So, Barber

di Sant'Agnese, P. A., and Talamo, R. C. (1967). New England fournal of Medicine, 277, 1287, 1343, 1399.

Dische, Z. (1964). In Research on Pathogenesis of Cystic Fibrosis, ed. P. A. di Sant'Agnese.

Gow, B. S. (1965). Fournal of Dental Research, 44, 885.

Gugler, E., Pallavicini, C. J., Swerdlow, H., and di Sant'Agnese, P. A. (1967) fournal of Pediatrics, 71, 585.

Kopito, L., and Shwachman, H. (1964). Nature, 202, 501.

Kopito, L., and Shwachman, H. (1966). Fournal of Pediatrics, 68, 313.

Kuhn, J. P., Rosenstein, B. J., and Oppenheimer, E. H. (1970). Radiology, 97, 59.

Kwart, H., and Shashoua, V. E. (1957). Transactions of the Nerw York Academy of Sciences, 19, 595.

Mandel, I. D., et al. (1969). Clinical Pediatrics, 8, 161 .
Neuman, W. F., and Neuman, M. W. (1958). The Chemical Dynamics of Bone Mineral, University of Chicago Press.

Rule, A. H., Kopito, L., and Shwachman, H. (1970). Fertility and Sterility, 21,515 . 